\title{
Improving the quality of perinatal and infant necropsy examinations: a follow up study
}

\author{
G M Vujanić, P H T Cartlidge, J H Stewart
}

\begin{abstract}
Aim-To compare the quality of perinatal and infant necropsy examinations in 1996 with those performed in 1993.

Methods-Cohort analysis, with data from the All Wales Perinatal Survey, of 1027 deaths (540 in 1993; 487 in 1996) of babies between 20 weeks' gestation and one year of age. The quality of the necropsy was assessed by scoring aspects identified as being part of the investigation.

Results-Necropsy was performed in 335 cases $(62 \%)$ in 1993 and in 320 cases $(66 \%)$ in 1996 . The proportion done in a regional centre increased significantly from $39 \%$ $(131 / 335)$ in 1993 to $76 \%(243 / 320)$ in 1996 $(\mathbf{p}<0.0001)$. The quality of necropsy was above the minimum standard in $54 \%$ of cases in $1993(171 / 314)$ compared with $93 \%$ in $1996(289 / 312)$ ( $p<0.0001)$. Improvement occurred in all categories. For stillbirths, 35\% (46/133) were above the minimum standard in 1993 compared with $90 \%(104 / 116)$ in 1996 ( $p<0.0001)$; for cases not classified as sudden unexpected death in infancy (SUDI), the improvement was from $62 \%$ in $1993(40 / 65)$ to $97 \%$ in $1996(73 / 75)(p<0.0001)$; and for SUDI cases, the improvement was from $32 \%$ in $1993(10 / 31)$ to $91 \%$ in $1996(21 / 23)$ $(p<0.0001)$. The quality of both nonregional and regional necropsies improved. For non-regional cases, the score was above the minimum standard in $28 \%$ (51/183) in 1993 compared with $69 \%(52 / 75)$ in 1996 ( $p<0.0001)$; for regional cases it improved from $92 \%(120 / 131)$ in 1993 to $100 \%(237 / 237)$ in 1996 ( $p<0.0001)$.
\end{abstract}

Conclusions-The quality of perinatal and infant necropsies improved considerably between 1993 and 1996, reflecting better awareness of the importance of good quality examination and an increase in referrals to paediatric centres.

(f Clin Pathol 1998;51:850-853)

Keywords: audit; perinatal; infant; necropsy

A necropsy examination is important in identifying the cause of death and as a means of auditing clinical practice. Clinically significant information found at necropsy has been reported in $14-46 \%$ of perinatal and infant examinations, and in many cases it discloses the cause of death. ${ }^{1-5}$ The quality of the necropsy examination is also important since clinically relevant information is more likely to emerge from a high quality investigation. ${ }^{1}$ Yet the quality of many perinatal and infant necropsies has been criticised. The Confidential Enquiry into Stillbirths and Deaths in Infancy (CESDI) found that $43 \%$ of necropsy reports were less than adequate. ${ }^{6}$ The Clothier inquiry into the circumstances surrounding the Allitt murders also criticised the pathological investigations and made a recommendation that all necropsy examinations of children dying suddenly and unexpectedly should be done by a paediatric pathologist. ${ }^{7}$ Systematic reviews of the quality of necropsy examinations have confirmed the problem. In Wales, we found that $46 \%$ of perinatal and infant necropsies done during 1993 were below the desired standard, ${ }^{8}$ and similar findings have been reported from West Midlands, East Anglia, Northern England, and Northern Ireland. ${ }^{5-11}$

There have been several changes in recent years aimed at improving the situation. In 1993 the Royal College of Pathologists issued Guidelines for Postmortem Reports to update a working party report on fetal and perinatal pathology published in $1988 . .^{12} 13$ The CESDI annual reports and other publications have highlighted the importance of a high quality necropsy and encouraged the use of a more centralised and specialist service. ${ }^{67}$ In Wales, we also convened regional and local seminars to highlight the value of a high quality necropsy investigation and emphasised that it should either be done according to the College's Guidelines or referred to a regional paediatric pathology centre where all necessary facilities were available. In this paper we re-evaluate the quality of perinatal and infant necropsy examinations in the light of these initiatives, by comparing the quality of the examinations performed in a geographically defined population in 1996 with those done in $1993 .{ }^{8}$

\section{Methods}

Subjects were identified using the All Wales Perinatal Survey, an ongoing population based surveillance of all deaths between 20 completed weeks of gestation and one year of age. ${ }^{14}$ Wales has a population of nearly three million and about 36000 births annually. In south Wales there are densely populated urban areas, in contrast to the large rural areas of Powys, Dyfed, and Gwynedd. Perinatal care is delivered by 16 consultant obstetric units and 11 general practitioner units within Wales, and several hospitals in neighbouring English health districts. Perinatal and infant pathology services are provided either by the local pathologist, or by a regional paediatric pathologist, and copies of necropsy reports are sent to the perinatal survey office. 
Table 1 Scoring system for the quality of perinatal and infant necropsy examination

\begin{tabular}{|c|c|}
\hline Category & Score \\
\hline Body weight & 20 \\
\hline Crown-rump/heel length & 20 \\
\hline Head circumference & 20 \\
\hline Foot length & 20 \\
\hline Gestational age assessment & 20 \\
\hline Organ weights $(\text { main })^{\star}$ & 40 \\
\hline Organ weights (other) & 40 \\
\hline Normal values & 20 \\
\hline Histology (main organs) ${ }^{\star}$ & 50 \\
\hline Histology (other organs) & 50 \\
\hline Placenta, macroscopic examination & 50 \\
\hline Placenta, histology & 50 \\
\hline Radiology & 100 \\
\hline Microbiology & 100 \\
\hline $\begin{array}{l}\text { Other relevant investigations (eg, cytogenetics, } \\
\text { biochemistry) }\end{array}$ & 100 \\
\hline
\end{tabular}

^Brain, liver, lungs, heart.

The cases were divided into four groups: fetal deaths at 20 to 23 weeks of gestation, stillbirths, sudden unexpected deaths in infancy (SUDI), and other infant deaths (non-SUDI). As in our previous study, the quality of each necropsy report was assessed using a modification of the system described by Rushton, which objectively scores aspects identified by the Royal College of Pathologists as being part of a necropsy (table 1). ${ }^{9}{ }^{12}$ Six aspects of the infant necropsy (body measurements, organ weights, histology, radiology, microbiology, other relevant investigations) were assessed, giving a maximum score of 600 . The necropsy after a fetal death should also include an examination of the placenta, so the maximum score was 700. The minimum acceptable score was also based on the Royal College of Pathologists guidelines, and for the fetal necropsy it was set at 350 (body measurements, organs weights, main organ histology, and examination of the placenta). The infant necropsy does not include the placental examination and so the minimum acceptable score for non-SUDI cases was 250. The necropsy for SUDI cases needs to be more detailed and so the minimum acceptable score was set at 350 .

Statistical analysis used $95 \%$ confidence intervals for the means, and the $\chi^{2}$ test to compare two proportions.

Results

A necropsy examination was performed on $62 \%$ of cases in $1993(335 / 540)$ compared with
$66 \%(320 / 487)$ in 1996 . The proportion done in a regional paediatric pathology centre increased significantly from $39 \%(131 / 335)$ in 1993 , to $76 \%(243 / 320)$ in 1996 ( $\mathrm{p}<0.0001)$. In 20-23 weeks' gestation fetal deaths it increased from $84 \%(71 / 85)$ to $92 \%(90 / 98)$, in stillbirths from $23 \%(31 / 135)$ to $69 \%$ (81/ $118)$, in non-SUDI cases from $29 \%(22 / 75)$ to $70 \%(57 / 81)$, and in SUDI cases from $18 \%$ $(7 / 40)$ to $65 \%(15 / 23)$.

Twenty two necropsy reports were unavailable for assessment, and in seven cases only a limited necropsy examination was performed, so 626 cases (314 in 1993, and 312 in 1996) were included in the analysis. Overall the scores for the quality of the necropsy report increased significantly from a mean (95\% confidence interval) of 306 (289 to 322) in 1993 to 454 (444 to 464 ) in 1996, with significantly higher scores in each subgroup of cases (table 2).

Scores for the quality of the necropsy report were above the minimum acceptable score in $54 \%$ of cases in $1993(171 / 314)$ compared with $93 \%(289 / 312)$ in 1996, a highly significant increase $(p<0.0001)$. The proportion with a quality score above the minimum acceptable level improved in stillbirths from 35\% (46/133) in 1993 to $90 \%(104 / 116)$ in 1996 $(\mathrm{p}<0.0001)$; in non-SUDI cases from $62 \%$ $(40 / 65)$ to $97 \%(73 / 75)(p<0.0001)$; and in SUDI cases from $32 \%(10 / 31)$ to $91 \%(21 / 23)$ $(\mathrm{p}<0.0001)$. The proportion of $20-23$ week fetal deaths with a score above the minimum acceptable level was similar in 1993 (88\%) and 1996 (93\%).

The quality score for necropsy reports from both non-regional pathology and regional paediatric pathology services improved between 1993 and 1996. The score for the non-regional necropsy reports increased significantly from 228 (210 to 246) in 1993 to 349 (327 to 371 ) in 1996 , and the proportion of scores above the minimum acceptable level improved from $28 \%$ $(51 / 183)$ to $69 \%(52 / 75)$ ( $p<0.0001)$. Similarly, for regional cases the score increased from 414 (399 to 430 ) in 1993 to 487 (481 to 494 ) in 1996 , with the proportion above the minimum acceptable score improving from 92\% (120/ $131)$ to $100 \%(237 / 237)(\mathrm{p}<0.0001)$.

Changes also occurred in the provision of necropsy services in individual hospitals. In

Table 2 Quality of perinatal and infant necropsy examinations in 1993 and 1996

\begin{tabular}{|c|c|c|c|c|c|c|}
\hline \multirow[b]{2}{*}{ Category } & \multicolumn{3}{|c|}{1993} & \multicolumn{3}{|c|}{1996} \\
\hline & $n$ & $\begin{array}{l}\text { Mean score } \\
(95 \% \mathrm{CI})\end{array}$ & $\begin{array}{l}\text { No of necropsies } \\
\text { above } M A S\end{array}$ & $n$ & $\begin{array}{l}\text { Mean score } \\
(95 \% \mathrm{CI})\end{array}$ & $\begin{array}{l}\text { No of necropsies } \\
\text { above } M A S\end{array}$ \\
\hline Overall & 314 & $\begin{array}{l}306 \\
\text { (289 to } 322)\end{array}$ & $171(54 \%)$ & 312 & $\begin{array}{l}454 \\
(444 \text { to } 464)\end{array}$ & $289(93 \%)$ \\
\hline 20-23 week fetal deaths & 85 & $\begin{array}{l}419 \\
\text { (397 to } 440 \text { ) }\end{array}$ & $75(88 \%)$ & 98 & $\begin{array}{l}485 \\
(473 \text { to } 498)\end{array}$ & $91(93 \%)$ \\
\hline Stillbirths & 133 & $\begin{array}{l}263 \\
\text { (237 to } 288 \text { ) }\end{array}$ & $46(35 \%)$ & 116 & $\begin{array}{l}454 \\
(437 \text { to } 474)\end{array}$ & $104(90 \%)$ \\
\hline Non-SUDI & 65 & $\begin{array}{l}264 \\
(240 \text { to } 289)\end{array}$ & $40(62 \%)$ & 75 & $\begin{array}{l}413 \\
\text { (392 to } 433)\end{array}$ & $73(97 \%)$ \\
\hline SUDI & 31 & $\begin{array}{l}265 \\
(213 \text { to } 315)\end{array}$ & $10(32 \%)$ & 23 & $\begin{array}{l}460 \\
(421 \text { to } 499)\end{array}$ & $21(91 \%)$ \\
\hline Regional necropsy & 131 & $\begin{array}{l}414 \\
\text { (399 to } 430)\end{array}$ & $120(92 \%)$ & 237 & $\begin{array}{l}487 \\
(481 \text { to } 494)\end{array}$ & $237(100 \%)$ \\
\hline Non-regional necropsy & 183 & $\begin{array}{l}228 \\
(210 \text { to } 246)\end{array}$ & $51(28 \%)$ & 75 & $\begin{array}{l}349 \\
(327 \text { to } 371)\end{array}$ & $52(69 \%)$ \\
\hline
\end{tabular}

CI, confidence interval; MAS, minimum acceptable score; SUDI, sudden unexpected death in infancy. 
Table 3 Quality of perinatal and infant necropsy examinations in 1993 and 1996 according to the hospital of death

\begin{tabular}{|c|c|c|c|c|c|c|}
\hline \multirow[b]{2}{*}{$\begin{array}{l}\text { Hospital of } \\
\text { death }\end{array}$} & \multicolumn{2}{|l|}{1993} & \multicolumn{2}{|l|}{1996} & \multicolumn{2}{|c|}{ Differences in score } \\
\hline & $\begin{array}{l}\text { Regionally performed } \\
\text { necropsy (\%) }\end{array}$ & Mean score & $\begin{array}{l}\text { Regionally performed } \\
\text { necropsy (\%) }\end{array}$ & Mean score & Mean & $95 \% C I$ \\
\hline A & 21 & 184 & 92 & 507 & 323 & 275 to 371 \\
\hline $\mathrm{B}$ & 42 & 203 & 100 & 507 & 304 & 280 to 328 \\
\hline C & 22 & 211 & 100 & 505 & 294 & 253 to 335 \\
\hline D & 100 & 344 & 100 & 500 & 156 & 134 to 178 \\
\hline $\mathrm{E}$ & 56 & 370 & 100 & 500 & 130 & 106 to 154 \\
\hline F & 27 & 292 & 100 & 492 & 200 & 182 to 218 \\
\hline G & 40 & 202 & 100 & 478 & 276 & 220 to 332 \\
\hline $\mathrm{H}$ & 97 & 323 & 100 & 463 & 140 & 122 to 158 \\
\hline I & 13 & 170 & 89 & 453 & 283 & 228 to 338 \\
\hline $\mathrm{J}$ & 44 & 270 & 75 & 447 & 177 & 151 to 203 \\
\hline $\mathrm{K}$ & 38 & 265 & 37 & 424 & 159 & 123 to 195 \\
\hline $\mathrm{L}$ & 33 & 259 & 60 & 419 & 160 & 111 to 209 \\
\hline$M$ & 0 & 237 & 17 & 418 & 181 & 128 to 234 \\
\hline $\mathrm{N}$ & 0 & 228 & 40 & 406 & 178 & 77 to 279 \\
\hline $\mathrm{O}$ & 0 & 230 & 33 & 393 & 163 & -86 to 412 \\
\hline $\mathrm{P}$ & 0 & 165 & 13 & 344 & 179 & 153 to 205 \\
\hline
\end{tabular}

CI, confidence interval.

1993, only three of 16 hospitals were using the regional paediatric pathology services for $50 \%$ or more necropsy examinations compared with $11 / 16$ in 1996 (table 3). This change was reflected in an improvement in the quality score in all hospitals dealing with fetal and infant deaths.

\section{Discussion}

The quality of perinatal and infant necropsy examinations in Wales has improved significantly in recent years. In 1993 the standard of necropsies in stillbirths and infant deaths was poor, although the quality of examinations in late fetal losses (20-23 weeks' gestation), most of which were done in a regional paediatric pathology centre, was satisfactory. ${ }^{8}$ By contrast, good quality necropsies were performed on $90 \%$ or more stillbirths and infant deaths in 1996, and the standard of the examination on late fetal losses was also better. Improvement was most pronounced for necropsies in SUDI, a particularly important change since a thorough and detailed necropsy examination is, by definition, mandatory for the diagnosis of sudden infant death syndrome. This coincided with an increased use of the regional paediatric pathology services from $18 \%$ to $65 \%$, although the recommendation in the Clothier reportthat a paediatric pathologist should be involved in the investigation of all such deaths - was not achieved. ${ }^{7}$ Further, although these results are very encouraging, they should not be regarded as fully satisfactory, as SUDI necropsy examinations should be very detailed and always include body measurements, external and internal examinations, weight of all major organs, histology of all organs, bacteriology, and $x$ ray skeletal survey. Using these more stringent criteria, $30 \%$ of cases (including $7 \%$ of cases done in a regional centre and $75 \%$ in non-regional centres) would have been unacceptable.

The previous poor quality of necropsy examinations and falling necropsy rates were perceived to reflect the low priority given to the investigation. ${ }^{1815}$ This was shown to be inappropriate by the demonstration that clinically important information is more likely to emerge from a good quality necropsy. ${ }^{18}$ At the same time, guidelines for reporting necropsy findings were published, and the use of specialist perinatal pathology services encouraged, particularly for complex cases. ${ }^{6-8} 12$ Dissemination of these findings resulted in a sharp increase in the use of centralised services in Wales, from $39 \%$ of necropsies in 1993 to $76 \%$ in 1996 . It may also have halted or maybe reversed the declining necropsy rate.

The higher standard of necropsy examinations in Wales was not only due to a centralisation of paediatric pathology services; the quality of investigations improved regardless of where they were performed. In non-regional centres, $69 \%$ of necropsies were of a good standard in 1996 , compared with only $28 \%$ in 1993, and a smaller but significant improvement was also evident in regional centres, from $92 \%$ being of good quality in 1993 to $100 \%$ in 1996. We speculate that this was the result of an increased use of the Royal College of Pathologists guidelines, and a higher priority being given to perinatal and infant necropsies.

CONCLUSION

Significant improvements in the quality of perinatal and infant necropsy examinations correlate with an increased use of specialist paediatric pathology services. Moreover, the standard of necropsies in general is improved by highlighting the importance of the investigation. Nevertheless, we have used minimum standard to assess the quality of perinatal and infant necropsies, and the data are reported anonymously. Further improvement requires the identification of individual poor performers to allow remedial action to be taken.

We thank local convenors, district coordinators and pathologists for their help with data collection, and Professor G T Williams for reviewing the manuscript. We also wish to thank Mrs J M Hopkins, the Survey administrator, for her support. The All Wales Perinatal Survey incorporates the Confidential Enquiry into Stillbirths and Deaths in Infancy and is funded by the Welsh Office.

1 Cartlidge PHT, Dawson AJ, Stewart JH, et al. Value and quality of perinatal and infant postmortem examinations: cohort analysis of 400 consecutive deaths. BMF 1995;310:155-8.

2 Shen-Schwarz S, Neish C, Hill LM. Antenatal ultrasound for fetal anomalies: importance of perinatal autopsy. Pediatr Pathol 1989;9:1-9.

3 Porter HJ, Keeling JW. Value of perinatal necropsy examination. F Clin Pathol 1987;40:180-4. 
4 Gau G. The ultimate audit. BMF 1977;i:1580-2.

5 Thornton CM, O'Hara MD. A regional audit of perinatal and infant autopsies in Northern Ireland. $\mathrm{Br} \mathcal{7}$ Obstet Gynaecol 1998;105:18-23.

6 Confidential Enquiry into Stillbirths and Deaths in Infancy. Annual report 1993. London: Department of Child Health, 1995.

7 Clothier C, MacDonald AC, Shaw DA. The Allitt inquiry. London: HMSO, 1994

8 Vujanić GM, Cartlidge PHT, Stewart JH, et al. Perinatal and infant postmortem examinations: how well are we doing? $f$ Clin Pathol 1995;48:998-1001.

9 Rushton DI. West Midlands perinatal mortality survey, 1987. An audit of 300 perinatal autopsies. Br $\mathcal{F}$ Obstet Gynaecol 1991;98:624-7.

10 East Anglian Region. Audit of perinatal pathology. East Anglian Regional Perinatal Survey and Confidential
Enquiry into Stillbirths and Deaths in Infancy (CESDI), annual report, 1993:62-7.

11 Wright C, Cameron H, Lamb W. A study of the quality of perinatal autopsy in the former Northern Region. $\mathrm{Br} f$ Obstet Gynaecol 1998;105:24-8.

12 Royal College of Pathologists. Guidelines for post mortem reports. London: RCPath, 1993.

13 Joint Working Party, RCOG/RCPath. Report on fetal and perinatal pathology. London: Royal College of Obstetricians perinatal pathology. London:
and Gynaecologists, 1988.

14 All Wales Perinatal Survey and Confidential Enquiry into Stillbirths and Deaths in Infancy. Annual report 1996. Cardiff: Perinatal Survey Office, Department of Child Health, University of Wales College of Medicine, 1997

15 Favara BE, Cottreau C, McIntyre L, et al. Pediatric pathology and the necropsy. Pediatr Pathol 1989;9:109-16. 